\title{
Development of MYMV Resistant Pre-breeding Lines in Mungbean (Vigna radiata) through Interspecific Hybridization
}

\author{
S. Chitra*, T. Kalaimagal and T. Thirumurugan \\ Department of Plant Breeding and Genetics, Anbil Dharmalingam Agricultural College and \\ Research Institute, Trichirappalli-620 009, Tamil Nadu, India \\ *Corresponding author
}

\section{A B S T R A C T}

Keywords

Pre-breeding,

Crossability,

MYMV, Vigna

stipulacea

Article Info

Accepted:

20 December 2017

Available Online:

10 January 2018
In agricultural crops, interspecific hybridization is a useful tool to introduce novel variations for desirable traits across species and to ultimately widen the available genetic variation. Mungbean yellow mosaic virus disease (MYMV) is a major devastating disease in mungbean crop. Non availability of resistant source in cultivated mung bean, the closely related semi-domesticated species viz., Vigna stipulacea with MYMV resistant genes could be introgressed in cultivated mungbean (Vigna radiata). In this study, wide hybridization was attempted between Vigna stipulacea and Vigna radiata to fill the gap in knowledge in terms of crossability and barriers if any between these two species. Successful hybrids were obtained by crossing between mungbean as female parent and Vigna stipulacea as male parent. Whereas, the reciprocal crosses failed to set hybrid seeds, indicating the presence of pre-fertilization barrier in those crosses. Further, evaluation of hybrids and segregating generation revealed reduced fertility, which suggests backcross as an ideal alternate option to introgress desirable alleles from Vigna stipulacea into mungbean.

\section{Introduction}

Mungbean is an important pulse crop in South and South East Asian counties as well as Australia. In India, mung bean occupies third important position among the pulse crops next to chickpea and pigeonpea. Because of short duration, low input requirement and high global demand it makes mungbean an ideal rotation crop in the rice based farming system. But this crop is most susceptible to MYMV disease which is prevalent in southern parts of India. The availability of resistant source for this disease in cultivated germplasm is limited and also unstable across different seasons. Among the Vigna species, Vigna stipulacea is one of the resistant species for MYMV and found along the bunds of rice fields of Tamil $\mathrm{Nadu}$, is characterized by extremely long peduncles that result in the flower and pod rising conspicuously above canopy (Tomooka et al., 2014). This species is often confused with Vigna trilobata. The crossability of Vigna stipulacea with other Vigna species was not elaborately studied till date. Hence, the present investigation was carried out to study 
the crossability of Vigna radiata cultivar $\mathrm{VBN}(\mathrm{Gg}) 2$ with Vigna stipulacea.

\section{Materials and Methods}

The most popular mungbean cultivar of Tamil Nadu state viz., VBN (Gg) 2, which is susceptible to the MYMV disease was crossed with Vigna stipulacea to develop MYMV resistant pre-breeding lines. Artificial hybridization was carried out with $V$. radiata (VBN (Gg) 2) as female parent and Vigna stipulacea (which was collected from paddy fields of Anbil Dharmalingam Agricultural College and Research Institute(TNAU), Tiruchirappalli, Tamil Nadu) as male parent as well as reciprocal crosses in Kharif' 2015 following the method suggested by Boling et al (1961). The total number of flowers pollinated, number of pods set and number of mature pods harvested were recorded. Abscised flowers within 24 hours after crossing were excluded on the basis of mechanical and natural damage during emasculation and pollination process. Pod set was calculated four days after pollination. Hybrid pods were observed to contain shriveled seeds in inter-specific crosses.

\section{Results and Discussion}

Wide hybridization enables the interspecific gene transfer, which may lead to the additional source of variation for the desirable characters. The present study was carried out to analyse the crossability relationship of Vigna radiata and Vigna stipulacea with the objective of transferring MYMV resistant genes from Vigna stipulacea to Vigna radiata. Hybridization experiment between Vigna radiata and Vigna stipulacea species revealed that forty five crossed pods were obtained from 267 crosses. The crossability percentage was only $16.8 \%$. The low crossed pod set percentage and poor filling of seeds revealed that there was no free crossing between these two species. Successful pod set was observed when Vigna radiata was used as female parent, but the reciprocal cross was not successful. The above results revealed that the barriers at the initial stage $i e$., prevention of pollen germination due to stigmatic exudates, disintegration of pollen tube and unfavourable interaction between cytoplasm and nucleus of a zygote could be possible reasons of the failure of reciprocal crosses (Subramanian and Muthiah, 2000) which has to be confirmed. Highest hybrid lethality of $84.3 \%$ was recorded in this cross combination which indicated the presence of undesirable linkages along with desirable characters (Table 1). The hybrid plant produced less number of pods and the seed per pod was less it varied from 36. Varying degree of success in inter-specific hybridization of Vigna has been reported by several researchers (Bharathi et al., 2006; Pandian et al., 2012; Mendioro et al., 1994; Satija and Ravi, 1996; Siddhu and Satija, 2003).

Table.1 Characteristics of V. radiata, V. stipulacea and interspecific hybrids

\begin{tabular}{|r|l|l|l|l|}
\hline S.No. & \multicolumn{1}{|c|}{ Particulars } & \multicolumn{1}{|c|}{ Vigna radiata } & \multicolumn{1}{|c|}{ Hybrid } & Vigna stipulacea \\
\hline 1. & Germination & Epigeal & Epigeal & hypogeal \\
\hline 2. & Growth habit & Erect & Erect & Trailing \\
\hline 3. & Leaf lobing & Deep & Shallow \& deep & Shallow \\
\hline 4. & Flower color & Bright yellow & Bright yellow & Bright yellow \\
\hline 5. & Matured Pod colour & Black & Black & Black \\
\hline 6. & Seed colour & Green & Green & Black \\
\hline 7. & Seed lusture & Shiny & Dull & Dull \\
\hline
\end{tabular}


Table.2 Crossability of Vigna radiata X Vigna stipulacea species

\begin{tabular}{|c|l|c|}
\hline S.No. & \multicolumn{1}{|c|}{ Particulars } & VBN $(\mathrm{Gg}) 2$ x Vigna stipulacea \\
\hline 1. & Number of crosses & 267 \\
\hline 2. & Number of crossed pods & 45 \\
\hline 3. & Crossabiltiy (\%) & 16.8 \\
\hline 4. & No. of hybrid seeds obtained & 176 \\
\hline 5. & No. of hybrid seeds germinated & 64 \\
\hline 6. & Germination (\%) & 36.4 \\
\hline 7. & $\begin{array}{l}\text { Number of plants harvested at } \\
\text { maturity }\end{array}$ & 10 \\
\hline 8. & Hybrid lethality & 84.3 \\
\hline
\end{tabular}

Fig.1 Morphology of interspecific hybrid and parents

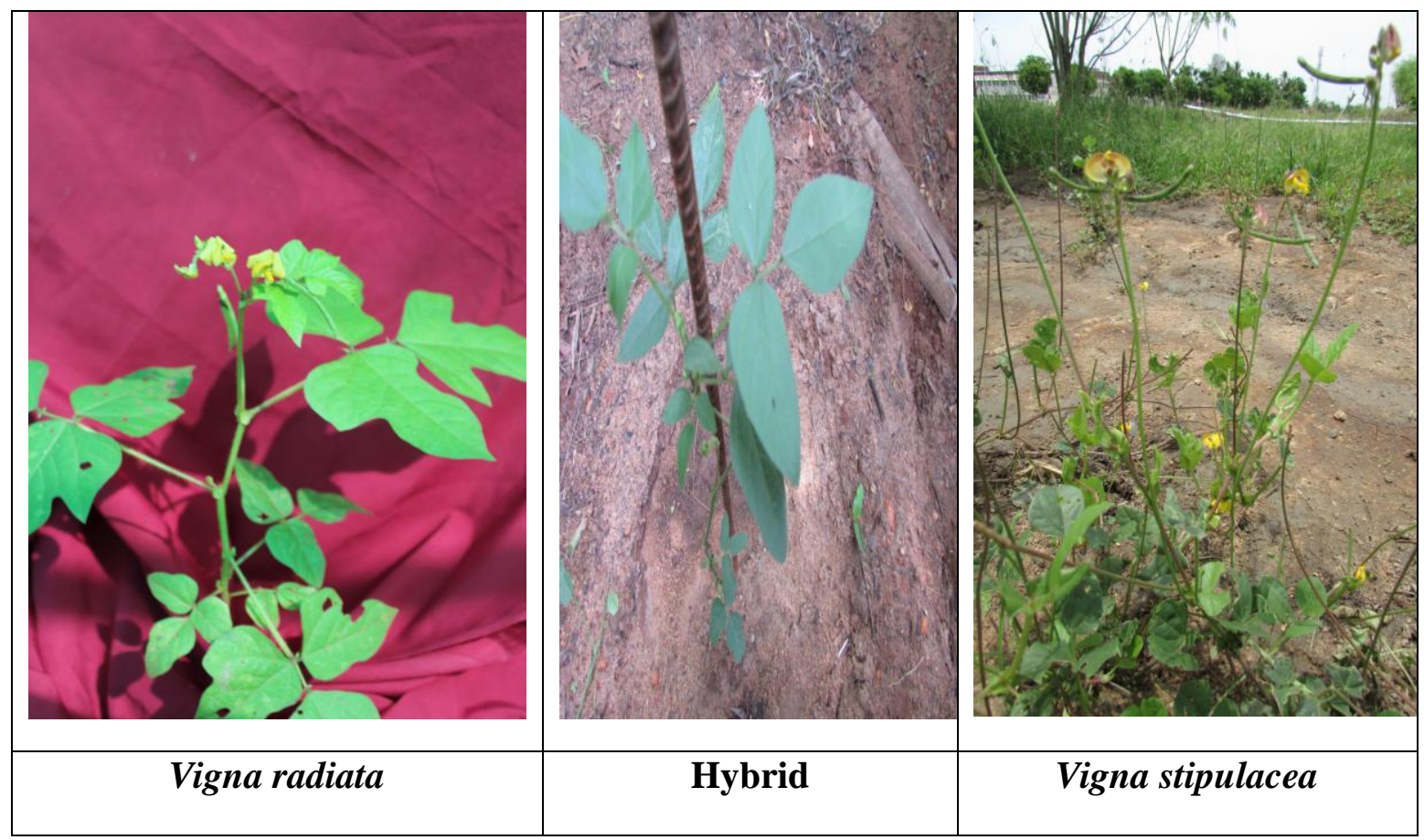

A total of 83 seeds were harvested from $10 \mathrm{~F}_{1}$ plants. Due to the low germination percentage of $\mathrm{F}_{2}$ seeds only 12 plants reached maturity stage. When considering growth habit of the plants in this cross, the female parent $(V$. radiata) was erect while male parent ( $V$. stipulacea) was trailing. But the $\mathrm{F}_{1}$ hybrids were erect while in $F_{2}$ generation, out 12 plants four were trailing in nature and the genetic could not inferred because of low germination of $F_{2}$ seeds.
The leaf lobing pattern of female parent $(V$. radiata) was deep whereas male parent $(V$. stipulacea) had shallow lobing pattern. The $\mathrm{F}_{1}$ plants expressed leaf lobing pattern of both the parents (Fig. 1). With regard to seed colour, female parent ( $V$. radiata) was shiny green but male parent ( $V$. stipulacea) expressed dull black whereas the hybrid seeds were dull green in nature (Table 2). In the $F_{2}$ generation, individual segregants were weak and produced less number of pods, ill filled 
pods and low germination percentage when compared to parental lines due to the presence of undesirable linkage drags. From the present study it could be concluded that the $F_{1}$ hybrids in this cross combination were usually found to be sterile or partially fertile and produce weak segregants in advanced generations.

Hence, to conclude, the low crossability and high hybrid lethality of this interspecific cross indicates the presence of fertilization barriers between Vigna radiata and Vigna stipulacea. Hence, further investigation is needed to delineate the barriers and ways to overcome the barriers for obtaining more crossed pods with minimum number of crosses. Backcross breeding was suggested while forwarding hybrids to the next generation to avoid undesirable linkages like trailing habit, less number of pods per plant, ill- filled pods and low germination percentage.

\section{Acknowledgement}

We thank Anbil Dharmalingam Agricultural College and Research Institute (TNAU), Tiruchirappalli for providing facilities to carry out this research.

\section{References}

Tomooka, N., T. Isemura, K.Naito, A. Kaga and Vaughan, D. 2014. Vigna species. In: Singh, M., I.S. Bisht and Dutta, M. (Eds.). Broadending Genetic base of grain legumes. Springer, India,
Chapter 9. pp. 175-208.

Bharathi, A., K.S. Vijay Selvraj, P. Veerabadhiran, Subba Lakshami, B. 2006. Crossability barriers in mungbean (Vigna radiata $\mathrm{L}$. Wilczek) with its wild relatives. Ind J Crop Sci. $1: 120-124$.

Boling, M., D.A.Sander and Matlock, R.S. 1961. Mungbean hybridization technique. Agron J. 53: 54 - 55.

Mendioro, M.S., and Ramirez, D.A. 1994. Post-fertilization barriers in interspecific hybridization (Vigna radiata (1.) Wilczek, V. mungo (L.) Hepper, $V$. glabrescens and their reciprocal crosses. Phil. Agric. 3: 359 - 382.

Pandiyan, M., N.Senthil, R.Suresh, N. Chakravarthy, D. Packiraj, Jagadeesh, S.2012. Interspecifi c hybridization of Vigna radiata $\times V$. trilobata. Wudpecker J Agr Res. 1: 233-234.

Satija, C.K., and Ravi .1996. Cytomorphological studies in hybrids and amphidiploids of $V$. radiata $\times$ $V$. umbellata. Crop Improv. 23: 19-24.

Sidhu, N., and Satija, C.K.2003. Cytomorphological characterization of amphidiploids of Vigna radiata $\mathrm{x} V$. umbellata. Crop Improv. 30 (1): 25 32.

Subramanian, A., and Muthiah, A.R. 2000. Interspecific hybridization between $V$. radiata (L.) Wilczek and blackgram $V$. mungo (L.) Hepper. Legume Res. 24(3): 154-158.

\section{How to cite this article:}

Chitra, S., T. Kalaimagal and Thirumurugan, T. 2018. Development of MYMV Resistant Prebreeding Lines in Mungbean (Vigna radiata) through Interspecific Hybridization. Int.J.Curr.Microbiol.App.Sci. 7(01): 2674-2677. doi: https://doi.org/10.20546/ijcmas.2018.701.320 